\title{
Nilai-Nilai Pembangun Karakter: Permainan Tradisional Karetan/Pelencatan Suku Using di Banyuwangi
}

\author{
Roudhotul Jannah, Arya Mahdi, Harjianto \\ Prodi PPKn FKIP Universitas PGRI Banyuwangi \\ Jalan Ikan Tongkol 22 Banyuwangi, 68416 \\ roudhotuli15@gmail.com, aryamahdi0771@gmail.com,hr.bwin@gmail.com
}

\begin{abstract}
The traditional game of karetan / pelencatan is the term of traditional game for Using tribe in Banyuwangi Regency. The traditional game of karetan / pelencatan uses a simple materials or tools from woven rubber bands (rubber bands strands). According to the size of agreement, usually about 3 or 4 meters in length, which is played in an open space and quite wide. The method used in this research is the ethnographic qualitative. This research examines the values of character building in traditional game of karetan / pelencatan in the community of Kemiren and Kabat village, whose the majority population is Using tribe. Data collection techniques used is observation, interview, and documentation. The result of the research on children's traditional games of karetan / pelencatan not only as a playing facility, but also as a medium to shape the children's character, such as; belief in the power of the One Almighty God, honesty in the game, hard work in achieving victory, national spirit, and interaction with the social environment.
\end{abstract}

Keywords: Character; Building Values

\section{PENDAHULUAN}

Pada era globalisasi saat ini, penguasaan teknologi menjadi prestise dan indikator kemajuan suatu bangsa. Bangsa dikatakan maju jika memiliki tingkat penguasaan teknologi tinggi (high technology), sedangkan bangsa-bangsa yang tidak bisa beradaptasi dengan kemajuan teknologi sering disebut sebagai negara gagal (failed country).

Perkembangan kemajuan teknologi berdampak tergerusnya permainan tradisional oleh permainan modern, seperti permainan video game, play station, game online berbagai permainan yang tersedia di komputer, handphone maupun laptop, dan permainan modern lainnya (Fauziah, 2015). Pola permainan anak mulai bergeser pada pola permainan di dalam rumah. Permainan yang dilakukan di dalam rumah lebih bersifat individual.

Permainan anak tradisional sangat banyak macamnya, seperti permainan egran, permainan engklek, permainan gobak sodor, permainan ular naga, dan beberapa permainan lainnya. Meskipun permainan tradisional sudah jarang ditemukan, masih ada permainan tradisional yang masih bertahan walaupun sangat jarang. Contoh permainan karetan/pelencatan. Dalam pembahasan ini penulis fokus pada permainan anak tradisional karetan/pelencatan.

Pada jaman sekarang permainan anak tradisional karetan/pelencatan sangat jarang ditemukan karena anak lebih memilih permainan modern, permainan modern tampilannya menarik dan instan (cepat). Begitu juga dengan anak suku Using di Banyuwangi mengalami nasib yang sama. Sangat ironis sekali kabupaten Banyuwangi yang kaya akan seni dan budaya akan tersingkir oleh budaya asing yang masuk ke Banyuwangi.

Permainan karetan/pelencatan adalah permainan yang memakai tali yang disusun dari karet gelang, permainan yang sangat favorit sekitar tahun 70, 80, hingga 90-an. Permainan karetan/pelencatan dilakukan di halaman sekolah atau setelah mandi sore di halaman rumah atau dilapangan. Sederhana tapi bermanfaat, bisa dijadikan sarana bermain juga sebagai sarana untuk membangun karakter anak seperti berinteraksi dengan lingkungan sosial.

Permainan anak tradisional merupakan salah satu budaya yang harus dilestarikan keberadaannya khususnya di Kabupaten Banyuwangi. Dalam permainan anak tradisional suku Using di kabupaten Banyuwangi terkandung nilai-nilai pendidikan karakter yang dapat membangun masyarakat yang berkarakter.

Berdasarkan penelitian di Harvard Universitas Amerika Serikat ternyata kesuksesan seseorang tidak ditentukan semata-mata oleh pengetahuan dan kemampuan teknis (hard skill) saja, tetapi oleh kemampuan mengelola diri dan orang lain (soft Skill). Penelitian ini mengungkapkan, kesuksesan hanya ditentukan sekitar $20 \%$ oleh hard skill dan sisanya $80 \%$ oleh soft skill. Bahkan orang-orang sukses di dunia bisa berhasil dikarenakan lebih banyak di dukung kemampuan soft skill daripada hard skill. Hal ini mengisyaratkan bahwa mutu pendidikan karakter peserta didik sangat penting untuk ditingkatkan soft skill ini merupakan bagian karakter yang harus dibentuk melalui pendidikan anak usia dini sampai dengan perguruan tinggi. (Wiyani, 2012:12)

Permainan tradisional karetan/ pelencatan merupakan berasal dari budaya nenek moyang yang diwariskan secara turun temurun. Oleh karena itu permainan tradisional yang seharusnya dilestarikan keberadaannya khususnya di Kabupaten Banyuwangi. Dalam permainan anak tradisional terkandung nilai-nilai pembangun karakter.

Berdasarkan latar belakang tersebut, penulis mengidentifikasi masalah yaitu bagaimana nilai-nilai pembangun karakter anak dalam permainan tradisional karetan/ pelencatan suku Using di Kabupaten Banyuwangi? Permasalahan yang dikaji ini sangat penting karena agar dapat mewujudkan masyarakat yang berkarakter.

\section{METODE PENELITIAN}

Bodgan dan Taylor (dalam Moleong, 1994:30) menyatakan penelitian kualitatif adalah prosedur 
penelitian yang menghasilkan data deskriptif berupa kata-kata tertulis dari orang atau perilaku yang diamati. Sedangkan Menurut Koentjaraningrat (1979: 329). Etnografi adalah jenis karangan yang terpenting yang mengandung bahan pokok dari pengolahan dan analisa antropologi. Isi sebuah karangan etnografi adalah suatu deskripsi mengenai kebudayaan suatu suku bangsa, namun di dunia ini ada suku-suku bangsa yang kecil yang terdiri dari hanya beberapa ratus penduduk tetapi juga ada suku-suku bangsa yang besar yang terdiri dari berjuta-juta penduduk, maka seorang ahli antropologi yang mengarang sebuah etnografi sudah tentu tidak dapat mencakup keseluruhan dari suku bangsa yang besar itu dalam deskripsinya.

Penelitian ini menggunakan rancangan penelitian Kualitatif Etnografi yaitu cara kerja dalam penelitian yang mendeskripsikan keadaan objek budaya atau suku tertentu berdasarkan fakta yang ada atau fenomena secara nyata dan nampak apa adanya. Mengacu pada definisi tersebut, dalam penelitian ini akan dijelaskan bentuk permainan/ dolanan anak Using, proses permainan/ dolanan anak Using, nilai-nilai pembangun karakter yang terkandung didalamnya. Data-data dalam penelitian ini adalah proses permainan/dolanan, konteks (gerakan dan benda-benda yang digunakan dalam permainan), dan video permaina/dolanan anak yang terdapat pada masyarakat Using di kabupaten Banyuwangi.

Sumber data dari penelitian ini adalah anak-anak, orang-orang dewasa hingga manula di Kabupaten Banyuwangi yang masa kecilnya sering bermain permainan/ dolanan yang sampai saat ini masih melestarikan permainan. Pengumpulan data menggunakan beberapa teknik yaitu teknik dokumentasi, teknik wawancara, dan teknik observasi.

\section{HASIL DAN PEMBAHASAN}

Kondisi Permainan tradisional karetan/pelencatan pada suku using di Kabupaten Banyuwangi pada umumnya terlahir dari budaya masyarakat yang saat ini mulai tergerus zaman. Dengan adaya teknologi yang mulai menjamur di masyarakat saat ini, permainan tradisional karetan/pelencatan kurang terjamaah lagi oleh anak-anak kecil dilingkungan Banyuwangi.

Hasil observasi, wawancara, dan dokumentasi permainan tradisional karetan/pelencatan pada masyarakat Using jarang ditemui di kabupaten Banyuwangi. Dalam keseharian anak-anak jarang bermain permainan tradisional karetan/pelencatan Permainan tradisional dimainkan anak-anak musiman, maksudnya tidak selalu ada seperti jaman dahulu.

Permainan karetan/pelencatan kebanyakan dimainkan oleh anak perempuan tapi tidak menutup kemungkinan jika anak laki-laki ikut bermain. Bahan atau alat yang digunakan adalah tali karet yang telah dianyam (untaian karet gelang) sesuai ukuran yang sesuai dengan kesepakatan biasanya panjangnya sekitar 3 atau 4 meter.

Cara bermainnya bisa dilakukan perorangan atau kelompok, jika hanya bermain seorang diri biasanya anak akan mengikatkan tali pada tiang atau apa pun yang memungkinkan lalu melompatinya, ataupun dipakai skipping (memegang kedua ujung tali kemudian mengayunkannya melewati kepala dan kaki sambil melompatinya). Jika bermain secara berkelompok biasanya melibatkan minimal tiga anak, dua anak akan memegang ujung tali; satu dibagian kiri, satu lagi dibagian kanan, sementara anak yang lainnya mendapat giliran untuk melompati tali karet. Tali karet direntangkan dengan ketinggian bergradasi, dari paling rendah hingga paling tinggi. Yang pandai melompat tinggi, dialah yang keluar sebagai pemenang.

Cara bermain permainan karetan/pelencatan, diantaranya:

1. Permainan karetan/pelencatan dimulai dengan hompimpa atau suit untuk menetapkan pemain yang bertugas menjadi pemegang ujung kanan dan kiri dan yang lainnya menjadi pelompat.

2. Semua pemain yang bertugas sebagai pelompat mendapat giliran melakukan lompatan dari tahapan pertama hingga tahapan terakhir, dan setiap tahapan terakhir, dan setiap tahapan dilakukan 2 kali Iompatan.

3. Semua pelompat yang mendapat giliran melompat tidak boleh menyentuh tali karet sesuai batas maksimal tahapan yang telah ditentukan oleh semua pemain.

4. Ada beberapa tahapan dalam permainan lompat tali karet (karetan/pelencatan) ini diantaranya : tahap setinggi mata kaki, tahap setinggi lutut, tahap setinggi pusar, tahap setinggi dada, tahap setinggi dagu, tahap setinggi telinga, tahap setinggi kepala, tahap setinggi tangan di ujung.

5. Setiap pemain yang mendapat giliran melompat tidak diperbolehkan memegang tali karet pada waktu melakukan lompatan.

6. Bila pemain mengenai tali pada tahap tertentu, maka pemain dinyatakan gagal melompat. Sehingga pemain tersebut harus berganti menjadi pemegang tali. Namun pemain tersebut bias melanjutkan giliran permainannya tadi (pada tahap ketika pemain melakukan pelanggaran), jika ada pemain berikutnya melakukan pelanggaran (pemain mengenai tali karet).

7. Permainan dinyatakan berakhir ketika pemain melakukan Iompatan sampai tahapan terkhir, lalu mengulangnya dari tahapan terendah kembali.

Variasi permainan karetan /pelencatan, diantaranya :

1. Permainan karetan/ pelencatan ini dilakukan sendirian (soliter) dengan cara mengikatkan tali pada pohon atau tiang ataupun dipakai skipping (memegang kedua ujung tali kemudian mengayunkannya melewati kepala dan kaki sambil melompatinya).

2. Permainan karetan/ pelencatan berkelompok biasanya pasti ada 2 orang anak yang harus memegang tali. Satu diujung sebelah kanan dan satu di ujung sebelah kiri, lalu meregangkannya. Sedangkan anak lainnya akan bermain melompati karet tersebut dengan jenjang kesulitan yang berbeda untuk tiap gradasi posisi bermain, apakah diangkat setinggi jongkok, pusar, dada, telinga 
maupun setinggi kepala anak.

\section{Pembahasan}

Penelitian yang dilakukan oleh Ifa $\mathrm{H}$. Misbach (2006) yang berjudul Peran Permainan Tradisional Yang Bermuatan Edukatif Dalam Menyumbang Pembentukan Karakter Dan Identitas Bangsa. Hasil penelitiannya adalah dalam permainan tradisional yang segala sesuatunya bersifat alamiah, dimana tidak ada setting yang dipersiapkan, anak menjadi lebih banyak mendapat kesempatan mengeksplorasi berbagai media yang tersedia alami sebagai dasar berpikir kreatif. Dalam permainan tradisional, anak lebih banyak dirangsang bermain dengan cara berinteraksi dengan orang lain di dalam kelompok. Dengan demikian, tidak dapat ditolak lagi bahwa permainan tradisional ini perlu dikembalikan fungsinya, sebagai salah satu sumbangan bagi pembentukan karakter dan identitas manusia Indonesia yang unggul dan tanggap terhadap perubahan tuntutan zaman tanpa tercabut dari identitas akar budayanya (Misbach)

Kementerian Pendidikan dan Kebudayaan (Kemdikbud), telah merumuskan 18 nilai pendidikan budaya dan karakter bangsa yang diharapkan untuk disampaikan kepada peserta didik dalam pendidikan formal. Nilai-nilai itu antara adalah: 1) religius, 2) jujur, 3) toleransi, 4) disiplin, 5) kerja keras, 6) kreatif, 7) mandiri, 8) demokratis, 9) rasa ingin tahu, 10) semangat kebangsaan, 11) cinta tanah air, 12) menghargai prestasi, 13) bershabat/komunikatif, 14) cinta damai, 15) gemar membaca, 16) peduli lingkungan, 17) peduli sosial, dan 18) tanggung jawab (Suryadi, 2013).

Hasil penelitian menunjukkan bahwa nilai-nilai pembangun karakter yang terkandung dalam permainan karetan/pelencatan meliputi:

\section{Religius}

Religius merupakan ketaatan dan kepatuhan dalam memahami dan $\mathrm{m}$ melaksanakan ajaran agama yang dianutnya, toleran terhadap pelaksanaan ibadah agama lain, dan hidup rukun dan berdampingan dengan pemeluk agama lain. Pada permainan karetan/pelencatan mengajarkan kepada pemainnya untuk berdo'a dan meyakini atas kekuasaan Tuhan ini tercrermin sebelum memulai permainan. Sebelum memulai permainan anak-anak selalu mengundi pemain dengan kalimat "hompimpa alaium gambreng". Ternyata bahasa itu berasal dari bahasa sang sekerta yang artinya dari Tuhan kembali ke Tuhan marilah kita bermain. Setelah mengundi dengan "hompimpa alaium gambreng" anak meyakini dapat urutan bermain berapa pun itu adalah kekuasaan Tuhan. Begitu juga dalam kehidupan anak agar selalu percaya atas kekuasaan Tuhan Yang Maha Kuasa bahwa kehidupan ini diatur oleh Tuhan.

2. Jujur

Jujur merupakan sikap dan perilaku yang mencerminkan kesatuan antara pengetahuan, perkataan, perbuatan (mengetahui apa yang benar, mengatakan yang benar, dan melakukan yang benar) sehingga menjadikan orang yang bersangkutan sebagai orang yang selalu dapat dipercaya dalam perkataan, tindakan, dan pekerjaan. Pada permainan karetan/pelencatan mengajarkan kepada pemainnya untuk jujur ini tercermin dalam permainan, pelompat permainan karetan/pelencatan tidak boleh menyentuh/menginjak tali karet sesuai batas maksimal tahapan yang telah ditentukan oleh semua pemain, apabila pelompat menyentuh atau menginjak maka berganti menjadi pemegang tali karet.

\section{Toleransi}

Toleransi merupakan sikap dan tindakan yang mencerminkan penghargaan terhadap perbedaan agama, aliran kepercayaan suku, etnis, pendapat, sikap, dan tindakan orang lain yang berbeda dari dirinya. Dalam permainan karetan/pelencatan anakanak tidak memandang hal-hal yang berkaitan dengan golongan ataupun kasta, agama, usia, warna kulit dan sebagainya. Dalam permainan karetan/pelencatan anak bermain membaur, bisa bermain dengan siapa pun asal berminat ikut dalam permainan karetan/pelencatan.

\section{Disiplin}

Disiplin merupakan tindakan yang menunjukkan perilaku tertib dan patuh pada berbagai ketentuan dan peraturan. Pada permainan karetan/pelencatan tercermin dari sikap pemain yang tidak berbuat curang dan bersedia menggantikan pemegang tali jika melanggar peraturan yang telah ditetapkan dalam permainan.

\section{Kerja Keras}

Kerja keras merupakan tindakan yang menunjukkan perilaku tertib dan patuh pada berbagai ketentuan dan peraturan. Pada permainan karetan/pelencatan nilai kerja keras tercermin dari semangat pemain yang berusaha agar dapat melompati tali dengan berbagai macam tahapan ketinggian.

\section{Kreatif}

Kreatif merupakan Berpikir dan melakukan sesuatu untuk menghasilkan cara atau hasil baru dari sesuatu yang telah dimiliki. Gerakan-gerakan permainan karetan/pelencatan bermacam-macam ada yang lompat biasa, lanangan, seplangan. Karetan/pelencatan bisa dilakukan sendiri atau bisa juga dengan berkelompok.

\section{Mandiri}

Mandiri merupakan sikap dan perilaku yang tidak mudah tergantung pada orang lain dalam menyelesaikan tugas-tugas. Pada permainan karetan/pelencatan semangatnya anak-anak untuk mandiri melompati tali karet dengan baik.

\section{Demokratis}

Demokratis merupakan cara berfikir, bersikap, dan bertindak yang menilai sama hak dan kewajiban dirinya dan orang lain. Pada permainan karetan/pelencatan terbukti dengan cara memilih dan menentukan jenis permainan, harus mengikuti tata tertib atau aturan yang disepakati. Semua dilakukan secara berunding atau musyawarah secara sukarela dan tidak ada paksaan atau tekanan dari luar, contohnya dengan hompimpa atau suit. 


\section{Rasa ingin tahu}

Rasa ingin tahu merupakan sikap dan tindakan yang selalu berupaya untuk mengetahui lebih mendalam dan meluas dari sesuatu yang dipelajarinya, dilihat, dan didengar. Pada permainan karetan/pelencatan sebelum permainan karetan/pelencatan di mulai salah satu pemain atau anak yang paling besar atau usianya yang paling tua yang lebih tahu menjelaskan aturan main. Sedangkan pemain lainnya mendengarkan dan menyimak.

\section{Semangat kebangsaan}

Semangat kebangsaan merupakan cara berpikir, bertindak, dan berwawasan yang menempatkan kepentingan bangsa dan negara di atas kepentingan diri dan kelompoknya. Pada permainan karetan/pelencatan pemain memainkan permainan karetan/pelencatan dengan baik, selain itu pemain juga mematuhi aturan permainan karetan/pelencatan yang sudah disepakati.

\section{Cinta tanah air}

Cinta tanah air merupakan cara berpikir, bertindak, dan berwawasan yang menempatkan kepentingan bangsa dan negara di atas kepentingan diri dan kelompoknya. Dengan memainkan permainan karetan/pelencatan ini secara tidak langsung dapat melestarikan kebudayaan Indonesia.

\section{Menghargai prestasi}

Menghargai prestasi merupakan sikap dan tindakan yang mendorong dirinya untuk menghasilkan sesuatu yang berguna bagi masyarakat, dan mengakui, serta menghormati keberhasilan orang lain. Pada permainan karetan/ pelencatan pemain yang belum dapat menyelesaikan permainan sampai tahap akhir menghargai pemain yang telah berhasil menyelesaikn tahap akhir.

\section{Bersahabat/komunikatif}

Bersahabat atau komunikatif merupakan sikap dan tindakan yang mendorong dirinya untuk menghasilkan sesuatu yang berguna bagi masyarakat, dan mengakui, serta menghormati keberhasilan orang lain. Permainan karetan/pelencatan yang dilakukan secara berkelompok anak membutuhkan teman.

\section{Cinta Damai}

Cinta damai merupakan sikap dan tindakan yang mendorong dirinya untuk menghasilkan sesuatu yang berguna bagi masyarakat, dan mengakui, serta menghormati keberhasilan orang lain. Tidak marah atau emosi ketika tidak bisa melanjutkan ke tahapan berikutnya.

\section{Gemar Membaca}

Gemar membaca merupkan kebiasaan menyediakan waktu untuk membaca berbagai bacaan yang memberikan kebajikan bagi dirinya. Dalam permainan karetan/pelencatan pemain secara tidak langsung diajarkan untuk gemar membaca ini tercermin waktu permainan jenis lompatan bermacam variasinya ada lanangan, congklakan. Dalam melompati tali dibutuhkan kosentrasi agar tidak mengenai atau menginjak tali.

16. Peduli Lingkungan
Peduli lingkungan merupakan sikap dan tindakan yang selalu berupaya mencegah kerusakan pada lingkungan alam di sekitarnya, dan mengembangkan upaya-upaya untuk memperbaiki kerusakan alam yang sudah terjadi. Pada permainan karetan/pelencatan bahan dan alat yang digunakan berasal dari gelang karet yang diuntai menjadi sebuah tali, tali karet ramah dengan lingkungan.

\section{Peduli sosial}

Peduli sosial merupakan sikap dan tindakan yang selalu ingin memberi bantuan pada orang lain dan masyarakat yang membutuhkan. Pada permainan karetan/ pelencatan ketika semua anggota kelompok gagal melakukan lompatan, maka anggota kelompok lain mendapatkan giliran melakukan lompatan kembali, dengan melanjutkan lompatan yang sebelumnya belum diselesaikan dengan melanjutkannya.

18. Tanggung jawab

Tanggung jawab merupakan sikap dan perilaku seseorang untuk melaksanakan tugas dan kewajibannya, yang seharusnya dia lakukan, terhadap diri sendiri, masyarakat, lingkungan (alam, sosial dan budaya), negara dan Tuhan Yang Maha Esa. Pada permainan karetan/pelencatan setiap pemain dituntut untuk tenggung jawab atas tugasnya dalam permainan karetan/pelencatan seperti ada yang bertugas megang tali karet yang lainnya bertugas melompat.

\section{SIMPULAN}

Permainan anak tradisional karetan/pelencatan tidak hanya sebagai sarana bermain tapi juga sebagai media membentuk karakter anak. Hasil dari penelitian ini diperoleh 18 nilai-nilai pembangun karakter dalam permainan tradisional karetan/pelencatan yaitu: 1) religius, 2) jujur, 3) toleransi, 4) disiplin, 5) kerja keras, 6) kreatif, 7) mandiri, 8) demokratis, 9) rasa ingin tahu, 10) semangat kebangsaan, 11) cinta tanah air, 12) menghargai prestasi, 13) bershabat/ komunikatif, 14) cinta damai, 15) gemar membaca, 16) peduli lingkungan, 17) peduli sosial, dan 18) tanggung jawab.

Hasil penelitian ini diharapakan mampu memberikan pemahaman kepada masyarakat Banyuwangi tentang pentingnya permainan tradisional dalam membangun karakter.

\section{DAFTAR PUSTAKA}

Arikunto, Suharsimi. (2010). Prosedur Penelitian: Suatu Pendekatan Praktik. Jakarta: PT Rineka Cipta.

Illiyun, N. N. (2012), Pendidikan Karakter, Sebuah Agenda Perbaikan Moral Bangsa. Diakses 25 Pebruari 2013

Iswinarti. (2017). Permainan Tradisional: Prosedur dan Analisis Manfaat Psikologis. Malang: UMM Press Malang

Koentjaraningrat. (1992). Kebudayaan, Mentalitas dan Pembangunan. Jakarta : PT. Gramedia Pustaka Utama.

Moleong, Lexy. (2011). Metodologi Penelitian Kualitatif. Bandung: PT Remaja Rosdakarya. 
Mulyani, Novi. (2016). Super Asyik Permaianan Tradisional Anak Indonesia. Yogyakarta : Diva Press.

Nugrahastuti, Eka,dkk. (2016). Nilai-nilai karakter pada permainan tradisional. Prosiding Seminar Nasional Inovasi Pendidikan FKIP UNS. 265 - 273

Suryadi. (2013). Kementrian Pendidikan nasional. Strategi pembelajaran Pendidikan karakter. Bandung: Remaja Rosdakarya.

http://file.upi.edu/Direktori/FIP/JUR. PSIKOLOGI/19750 7292005012IFA HANIFAH

MISBACH/LAPORAN PENELITIAN PERAN PE RMAINAN TRADISIONAL REVISI FINAL .pdf diakses 7 Juni 2017 